\title{
A rare case of type IV dual left anterior descending artery and anomalous origin of the left coronary artery from the noncoronary sinus
}

\author{
Mahmood Tehrai, MD, and Bahare Saidi, MD
}

Dual left anterior descending artery (LAD) is a rare congenital anomaly. ${ }^{1}$ It consists of a short LAD that ends high in the anterior interventricular groove and a longer LAD that enters the distal anterior interventricular groove and feeds the apex. Herein we present a rare case of type IV dual LAD and anomalous origin of the left main coronary artery (LCA) from the noncoronary sinus.

\section{CLINICAL SUMMARY}

A 58-year-old woman with hypertension and right-sided body weakness underwent coronary computed tomography (CT) scan. The CT scan was perfomed by a 64-slice scanner (Somatom Sensation 64; Siemens Medical Solutions, Erlangen, Germany), which revealed that the LCA originated from the noncoronary sinus (Figure 1). In addition, the LAD had a dual origin, a small LAD arising from the LCA and a longer $\mathrm{LAD}$ arising from the proximal right coronary artery (RCA). The branch from the RCA gave rise to a right ventricular branch and passed anterior to the right ventricle and into the left ventricular apex (Figure 2). The short LAD supplied the diagonal branches and contained nonstenotic plaques. Both the short and long LADs provided septal perforator

From Day General Hospital, Tehran, Iran.

Disclosures: Authors have nothing to disclose with regard to commercial support. Received for publication Feb 19, 2011; accepted for publication March 3, 2011; available ahead of print May 13, 2011.

Address for reprints: Bahare Saidi, MD, Tavanir st, Vali Asr Ave, Day General

Hospital, Tehran, Iran (E-mail: bahare_saidi@yahoo.com).

J Thorac Cardiovasc Surg 2011;142:451-2

0022-5223/ $\$ 36.00$

Copyright (C) 2011 by The American Association for Thoracic Surgery doi:10.1016/j.jtcvs.2011.03.031 branches. The RCA was dominant. The patient was treated medically.

\section{DISCUSSION}

Spindola-Franco, Grose, and Solomon ${ }^{1}$ described 4 variations of the dual LAD. In type I, the long LAD runs on the anterior left ventricular wall, enters the anterior interventricular groove at the distal end, and supplies the apex; the short LAD runs high in the anterior interventricular groove. Type II has a similar pattern to type I, but the long LAD courses on the anterior right ventricular wall before entering the anterior interventricular groove. In type III, which is the rarest, the long LAD has an intramyocardial course. In type $\mathrm{IV}$, the long LAD arises from the right coronary artery and enters the distal anterior interventricular groove whereas the short LAD originates from the LCA and ends high in the anterior interventricular groove. ${ }^{1}$ Our patient had an unusual case of type IV dual LAD given the associated anomalous origin of the LCA from the noncoronary sinus.

Correct recognition of type IV dual LAD has clinical significance. During angiography, if a dual LAD is not suspected the short LAD can be mistaken for a mid-LAD stenosis. In addition, when these patients require revascularization, the correct placement of the arteriotomy depends on the knowledge regarding which of the long or short LADs is obstructive. When the short LAD is diseased, the exposure is made higher in the anterior interventricular groove; if both the short and long LADs are atherosclerotic, grafts to both arteries might be needed..$^{2}$ It should also be recognized
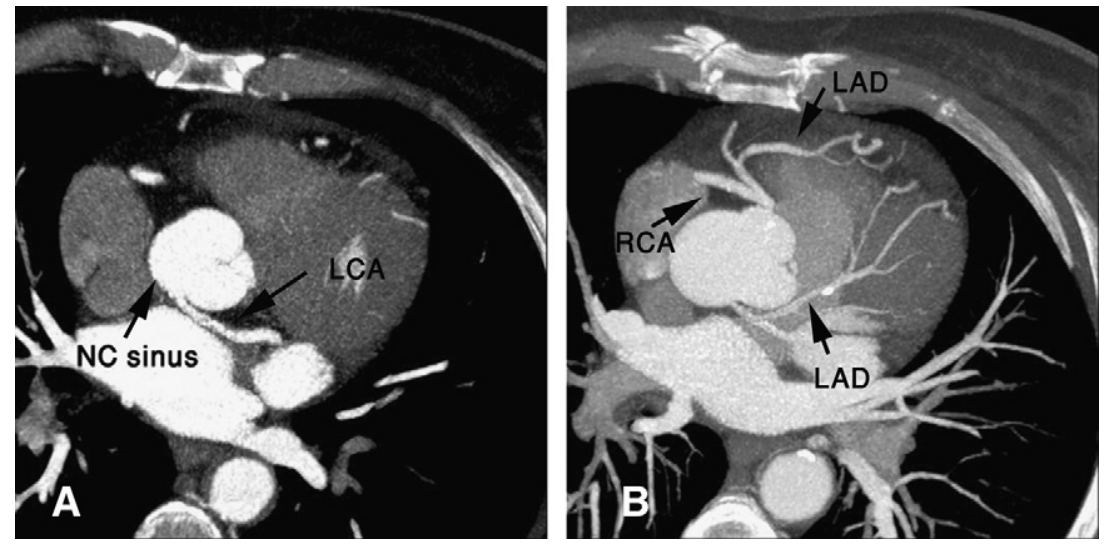

FIGURE 1. A, Axial view, the origin of the left main coronary artery $(L C A)$ from the noncoronary $(N C)$ sinus is illustrated. B, Maximal intensity projection, the long left anterior descending artery $(L A D)$ from the right coronary artery $(R C A)$ and the short LAD from the LMC are shown. 


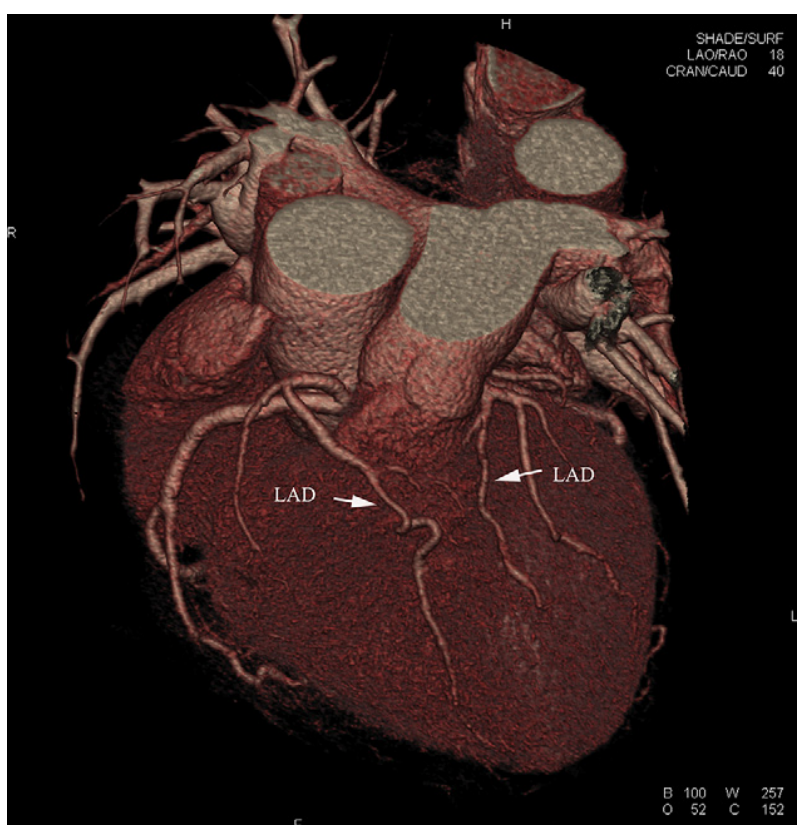

FIGURE 2. Multislice computed tomographic scan, volume rendered, left anterior oblique $(L A O)$ view, depicting the long left anterior descending artery $(L A D)$ from the right coronary artery and the short LAD from the left main coronary artery. RAO, Right anterior oblique.

that the presence of 2 LADs limits the extent of myocardial ischemia in cases of atherosclerosis. ${ }^{3}$

Anomalous origin of the LCA from the right coronary sinus or the pulmonary artery has been reported and can cause chest pain or syncope and in rare cases sudden death in young adults. ${ }^{4}$ The origin of the LCA from the noncoronary sinus is extremely uncommon. ${ }^{5}$ The symptoms related to anomalous origin of the LCA have been attributed to several factors: slitlike origin of the anomalous artery, the course of the coronary artery between the aorta and pulmonary artery, and an intramural course. ${ }^{6}$ As a result, surgery is generally recommended in the presence of symptoms to prevent sudden death. The origin of the LCA from the posterior sinus, on the other hand, is extremely uncommon. Very few cases have been reported and the clinical course is less clear. ${ }^{6}$ However, it should be suspected when the LCA cannot be selectively cannulated through the left coronary sinus. Liberman and associates ${ }^{5}$ reported a case of origin of the LCA from the noncoronary sinus presenting with ventricular arrhythmia. Although a cardiodefibrillator was implanted owing to an episode of aborted sudden cardiac death, the patient was not treated surgically for the correction of the coronary anomaly. The symptoms of our patient were not considered to be related to the coronary artery and she was also treated medically.

In this report we described the multidetector $\mathrm{CT}$ findings of an anomalous LCA from the noncoronary sinus in the presence of type IV dual LAD; to the best of our knowledge, this association has not been previously reported. Awareness of the presence of coronary anomalies is important when making decisions regarding coronary artery catheterization or surgical revascularization. Multisliced CT is gaining a valuable role in detecting coronary anomalies and demonstrating their origin and course.

\section{References}

1. Spindola-Franco H, Grose R, Solomon N. Dual left anterior descending coronary artery: angiographic description of important variants and surgical implications. Am Heart J. 1983;105:445-55.

2. Agarwal PP, Kazerooni EA. Dual left anterior descending coronary artery: CT findings. AJR Am J Roentgenol. 2008;191:1698-701.

3. Namboodiri N, Ajitkumar V, Tharakan J. A rare type of dual left anterior descending artery distribution demonstrated by multislice cardiac computerized tomography in a patient with anterior wall infarction. J Invasive Cardiol. 2008;20: $367-9$

4. Basso C, Maron BJ, Corrado D, Thiene G. Clinical profile of congenital coronary artery anomalies with origin from the wrong aortic sinus leading to sudden death in young competitive athletes. J Am Coll Cardiol. 2000;35:1493-501.

5. Liberman L, Pass RH, Kaufman S, Hordof AJ, Printz BF, Prakash A. Left coronary artery arising from the non-coronary sinus: a rare congenital coronary anomaly. Pediatr Cardiol. 2005;26:672-4.

6. Taylor AJ, Byers JP, Cheitlin MD, Virmani R. Anomalous right or left coronary artery from the contralateral coronary sinus: "high-risk" abnormalities in the initial coronary artery course and heterogeneous clinical outcomes. Am Heart J. 1997;133:428-35. 